\title{
High-Performance Liquid Chromatographic Analysis of Cyclosporine A in Human Skin
}

\author{
Aleš Husek ${ }^{\mathrm{a})}$, Ernst Eibler ${ }^{\mathrm{b} *}$, and Wolfgang Wiegrebe ${ }^{\mathrm{b})}$ \\ a) Department of Medical Chemistry, Medical Faculty, Palacky University, CS-77515 Olomouc, Czech Republic \\ b) Faculty of Chemistry and Pharmacy, University of Regensburg, D-8400 Regensburg, Germany
}

Received December 22, 1992

A three-dimensional high-performance liquid chromatography (HPLC) method is described for the determination of cyclosporine $\mathrm{A}$ in human skin. The method allows to determine at least $3 \mathrm{ng}$ cyclosporine $\mathrm{A}$ in 10 $\mathrm{mg}$ skin (total sample amount needed) and is suitable for cyclosporine A level monitoring in the skin of psoriatic patients.
HPLC-Bestimmung von Cyclosporin A in menschlicher Haut

Eine dreidimensionale HPLC-Methode zur Bestimmung von $\leq 3 \mathrm{ng}$ Cyclosporin A in $10 \mathrm{mg}$ menschlicher Haut wird beschrieben. Dieses Verfahren eignet sich zur Cyclosporin A Bestimmung in der Haut von Psoriatikern.
Cyclosporine A (CyA) is highly effective in the systemic treatment of psoriasis. The mechanism of CyA functioning in skin is not yet fully understood, but it is known that topical application has no clinical effect. However, by oral or intravenous application dose-related side-effects, particularly nephrotoxicity, appeared ${ }^{1)}$.

The purpose of this work was to develop an analytical method that would enable to investigate the relationship between the skin CyA level and the antipsoriatic effect by oral CyA application. To reduce the stress of the patients, the amount of skin sample should not exceed 10-20 mg.

Several methods of CyA determination in biological material were published, mostly based on HPLC or radioimmunoassay, but only few of them were used for skin analysis $^{1,2,3,4)}$. All these methods are of relatively low sensitivity and require large sample amounts (about $100 \mathrm{mg}$ ).

The CyA skin level was found to be approximately 3.5 $\mathrm{ng} / \mathrm{mg}$ wet weight by patients receiving a daily oral dose of $14 \mathrm{mg} / \mathrm{kg}^{4)}$. However, the common therapeutical doses are smaller; provided in such case the CyA level is equal to or less than $1 \mathrm{ng} / \mathrm{mg}$ tissue, the sensitivity required for the determination would be $10 \mathrm{ng} \mathrm{CyA} /$ sample and less.

Preliminary solid-phase extraction experiments on the 10 ng level failed. The skin extract purification step using common SPE procedures was not successful due to partially irreversible adsorption of the CyA on the cartridge. Several sorbents were used but the recovery was not reproducible and mostly less than $50 \%$. Only the multi-dimensional HPLC provided the required results.

\section{Materials and Methods}

Reagents and purity requirements

Skin extraction: $\mathrm{CH}_{3} \mathrm{CN}$ for spectroscopy (Uvasol, Merck, Darmstadt); chromatography: $\mathrm{CH}_{3} \mathrm{CN}$ of gradient HPLC grade (Baker), hexane and isopropanol of HPLC grade (Baker); water of LiChrosolv quality (Merck).
Cyclosporine A (batch No. 90166) and cyclosporine C (CyC, batch No. 27402) were kindly supplied by Sandoz. The concentrations of stock solutions were $0.94 \mathrm{ng} \mathrm{CyA} / \mu \mathrm{l} \mathrm{CH} \mathrm{CH}_{3} \mathrm{CN}$ and $1.115 \mathrm{ng} \mathrm{CyC} / \mu \mathrm{l} \mathrm{CH}_{3} \mathrm{CN}$.

The samples were handled in $4 \mathrm{ml}$ screwing cap vials with PTFE seal. All used glass was cleaned with chromosulfuric acid. $\mathrm{N}_{2}$ used for sample evaporation was of 5.0 quality with an all-steel pressure degradation vent.

\section{Skin extraction}

Skin used for recovery experiments originated from amputation. After separation it was frozen and then handled in two ways:

a) An approximately $0.5 \mathrm{~mm}$ thick upper layer was taken by lancet.

b) The epidermis only $(0.2 \mathrm{~mm})$ was separated by a microtome; the separation was controlled by microscopy.

$10-15 \mathrm{mg}$ skin sample and approximately $100 \mathrm{mg}$ quartz sand p.a. were placed in a small mortar, cooled with liquid $\mathrm{N}_{2}$ and homogenized after its evaporation. The mortar was let to warm up and the sample was further

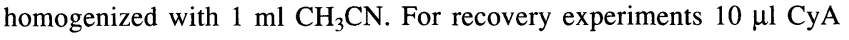
stock solution were added with this first $\mathrm{CH}_{3} \mathrm{CN}$ portion. The homogenate was transferred into a $4 \mathrm{ml}$ vial using Pasteur pipette, the vial was centrifuged at $1000 \mathrm{~g}$ for $3 \mathrm{~min}$. The supernatant was transferred using another Pasteur pipette into a $5 \mathrm{ml} \mathrm{PE}$ syringe and immediately passed through a $0.2 \mu \mathrm{m}$ filter into a scaled $10 \mathrm{ml}$ centrifuge tube.

Mortar and pestle were washed with $1 \mathrm{ml} \mathrm{CH}_{3} \mathrm{CN}$, the liquid was transferred to the sediment and the vial was vortexed for $30 \mathrm{~s}$ and centrifuged for $3 \mathrm{~min}$ at $1000 \mathrm{~g}$. The supernatant was filtered into the centrifuge tube and the wash step was repeated using sonication instead of vortexing.

The combined filtrate was evaporated on a $50^{\circ} \mathrm{C}$ water bath by a $\mathrm{N}_{2}$ stream to $0.3 \mathrm{ml}$ volume, and by slow vortexing $0.9 \mathrm{ml}$ water were added; the sample became slightly opalescent.

\section{Preparative HPLC}

Equipment

HPLC pump: model $6000 \mathrm{~A}$ (Millipore-Waters, Eschborn), equipped on the outlet with a cleaning precolumn $4 \times 60 \mathrm{~mm}$ dry-packed with 12-20 $\mu \mathrm{m}$ PRP-1 (Hamilton, Reno).- Injector: model U6K (Millipore-Waters) with $2 \mathrm{ml}$ loop.- Preparative column: A cartridge $4 \times 20 \mathrm{~mm}$ filled with 5 $\mu \mathrm{m}$ Spherisorb Alumina PC-18 (Bischoff Analysentechnik, Leonberg) was 


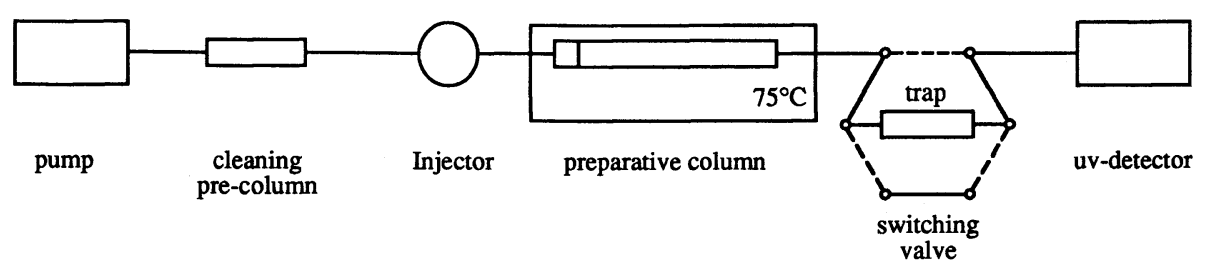

Fig. 1: Fluid system of the preparative chromatograph.

thermostated to $75^{\circ} \mathrm{C}$. Mobile phase: $\mathrm{CH}_{3} \mathrm{CN}-\mathrm{H}_{2} \mathrm{O} 29: 71$ with $\mathrm{NaOH}$ addition up to $0.2 \mathrm{mmol} / \mathrm{l}$ total concentration, flow rate $2 \mathrm{ml} / \mathrm{min}$.- Trap: 4 × 30 mm dry-packed with $12-20 \mu \mathrm{m}$ PRP-1, switched by Rheodyne 7000 vent.UV detector: SpectroMonitor 3200 (LDC Analytical GmbH, Gelnhausen), detection wavelength $212 \mathrm{~nm}, 1 \mathrm{~V}$ output, range $1 \mathrm{AU}$, response time $5 \mathrm{~s}$ (Fig. 1).- Integrator: DataJet (Spectra-Physics, Darmstadt), attenuation 2 $\mathrm{mV} /$ full scale, with the option of postrun integration (LABNET assisted by an ACER 910 personal computer).

\section{Sample collection}

The CyA analytical window was checked by injection of a mixture of approximately $100 \mu \mathrm{l} \mathrm{CyA} \mathrm{stock} \mathrm{solution}+0.2 \mathrm{ml} \mathrm{CH}_{3} \mathrm{CN}+0.9 \mathrm{ml} \mathrm{H}_{2} \mathrm{O}+$ $0.2 \mathrm{ml}$ mobile phase. Sample analysis was done with an identical mobile phase. The sample was filled into the injector loop and the centrifugation tube was washed with $0.2 \mathrm{ml}$ mobile phase, shortly vortexed with maximal intensity, and shortly centrifuged. The washing liquid was also filled into the injector loop and the whole sample was injected. In the CyA elution interval the trap was switched on.

\section{Trap handling}

After sampling has been completed, the trap was washed with $1 \mathrm{ml} \mathrm{H}_{2} \mathrm{O}$, approx. $1 \mathrm{~min}$ blown with $\mathrm{N}_{2}$ and eluted in the opposite direction with 0.5 $\mathrm{ml} \mathrm{CH}_{3} \mathrm{CN}$. The effluent was evaporated to dryness on a water bath at $50^{\circ} \mathrm{C}$ with a $\mathrm{N}_{2}$ stream. It was usefull to continue the $\mathrm{N}_{2}$-blowing for further $10 \mathrm{~min}$ so that the amount of volatile contaminants originated from $\mathrm{CH}_{3} \mathrm{CN}$ was reduced. The CyA recovery was not affected thereby. The residue was analysed by RP-HPLC.

\section{Column and trap washing}

After analysis the preparative column was washed at $75^{\circ} \mathrm{C}$ in the opposite direction together with the cleaning column at room temp. successively with $50 \mathrm{ml} \mathrm{CH} \mathrm{CH}_{3} \mathrm{CN}, 50 \mathrm{ml} \mathrm{CH} \mathrm{CN}_{3} \mathrm{H}_{2} \mathrm{O}$ 1:1 with $\mathrm{NaOH}$ addition up to $0.2 \mathrm{mmol} \mathrm{NaOH}$ total concentration, and $50 \mathrm{ml} \mathrm{CH}_{3} \mathrm{CN}$. The trap was washed in the opposite direction at room temp. with $50 \mathrm{ml} \mathrm{CH}_{3} \mathrm{CN}$ and 0.5 $\mathrm{ml} \mathrm{H}_{2} \mathrm{O}$.

\section{Reversed-phase analytical HPLC}

\section{Equipment}

HPLC pump: model $6000 \mathrm{~A}$ (Millipore-Waters).

A guard column 4 × $60 \mathrm{~mm}$ dry-packed with 37-50 $\mu \mathrm{m}$ Bondapak C-18 Corasil (Millipore-Waters) was thermostated to $70^{\circ} \mathrm{C}$. It was followed by an analytical pre- and main column $4 \times 20+250 \mathrm{~mm}$ filled with $5 \mu \mathrm{m}$ Spherisorb ODS II (Bischoff-Analysentechnik, $\mathrm{GmbH}$ ), thermostated to $70^{\circ} \mathrm{C}$. Mobile phase: $\mathrm{HCH}_{3} \mathrm{CN}-\mathrm{H}_{2} \mathrm{O} 71: 29$, flow rate $1.2 \mathrm{ml} / \mathrm{min}$.- Injector: model 7125 (Rheodyne, Berkeley) with $0.5 \mathrm{ml}$ loop.- For UV detector and integrator see Preparative HPLC.- Integrator attenuation $1 \mathrm{mV} /$ full scale.

\section{Calibration}

$10 \mu \mathrm{l} \mathrm{CyA} \mathrm{stock} \mathrm{solution} \mathrm{(external} \mathrm{standard)} \mathrm{and} 150 \mu \mathrm{l}$ mobile phase were introduced into a vial and vortexed for $30 \mathrm{~s}$, simulating the conditions for sample analysis. The solution was sucked into a $250 \mu 1$ syringe. $100 \mu \mathrm{l}$ mobile phase were used to wash the vial, sucked into the syringe and the complete sample was injected. To ensure higher determination accuracy the standard injection was repeated for at least three times. The medium CyA retention volume and the average calibration factor were determined from these chromatograms.

Sample analysis

The sample residue of the preparative collection was reconstituted analogously to the standard. During its analysis on the RP-HPLC analytical column the detector effluent was collected in the interval of the CyA analytical window, $10 \mu \mathrm{l} \mathrm{CyC}$ stock solution were added, and the effluent was immediately evaporated to dryness on a water bath at $50^{\circ} \mathrm{C}$ by a $\mathrm{N}_{2}$ stream. The residue was reanalysed in the following step.

Normal-phase HPLC

Equipment

HPLC-pump: model 114 M (Beckman Instruments, Munich).- Pre- and main column $4 \times 20+250 \mathrm{~mm}$ were filled with $5 \mu \mathrm{m}$ Hypersil CPS (cyanopropylsilica, Bischoff Analysentechnik $\mathrm{GmbH}$ ) and thermostated at $75^{\circ} \mathrm{C}$. Mobile phase: $10 \%$ isopropanol in hexane, flow rate $1 \mathrm{ml} / \mathrm{min}$.Injector, detector, and integrator see RP-HPLC.

The sample evaporated after RP-HPLC together with $\mathrm{CyC}$ as internal standard was sonicated for $10 \mathrm{~min}$ with $2 \mathrm{ml} \mathrm{CH}_{3} \mathrm{CN}$ in order to release the cyclosporine molecules adsorbed on the glass and the solution was evaporated to dryness on a water bath at $50^{\circ} \mathrm{C}$ by a $\mathrm{N}_{2}$ stream. The residue was reconstituted in $250 \mu \mathrm{l} 15 \% \mathrm{i}$-PrOH/hexane by $1 \mathrm{~min}$ vortexing and $3 \mathrm{~min}$ sonication and the solution was injected; the vial was not washed.

\section{Results and Discussion}

Both analytical and the preparative column were maintained at $70-75^{\circ} \mathrm{C}$ in order to accelerate the interconversion of the CyA conformers ${ }^{5)}$ and so to prevent peak broadening.

\section{Preparative HPLC}

The presented procedure requires a high degree of purity of all solvents and materials especially on account of working with a trap.

$\mathrm{CH}_{3} \mathrm{CN}$ of various qualities and of various origins was checked for impurities. In all lots three contaminants were found which, however, did not interfere with CyA. LiChrosolv water contained only a small quantity of a substance eluted in the CyA vicinity. By preparative HPLC it was possible to remove most of the mentioned contaminants using a short cleaning PRP-1 pre-column connected to the pump outlet.

Most of the skin matrix substances were found to be of acidic character. On a preparative octadecylsilane column with an acidic mobile phase they were strongly retained and 
the peaks were tailing as compared to neutral conditions. In these both cases, however, the CyA peak was overlapped by the skin matrix peaks. Only the application of an alkaline mobile phase and an alkaline-resistant sorbent (PRP-1 or Spherisorb Alumina PC-18) enabled the required separation (Fig. 2).

The preparative chromatography of the skin matrix was satisfactory provided only upper skin layer (epidermis and dermis) were taken. By analysis of the samples containing deeper skin layers or subcutaneous tissue the separation was not reliable and relative large peaks appeared in the CyA window (probably lipids).

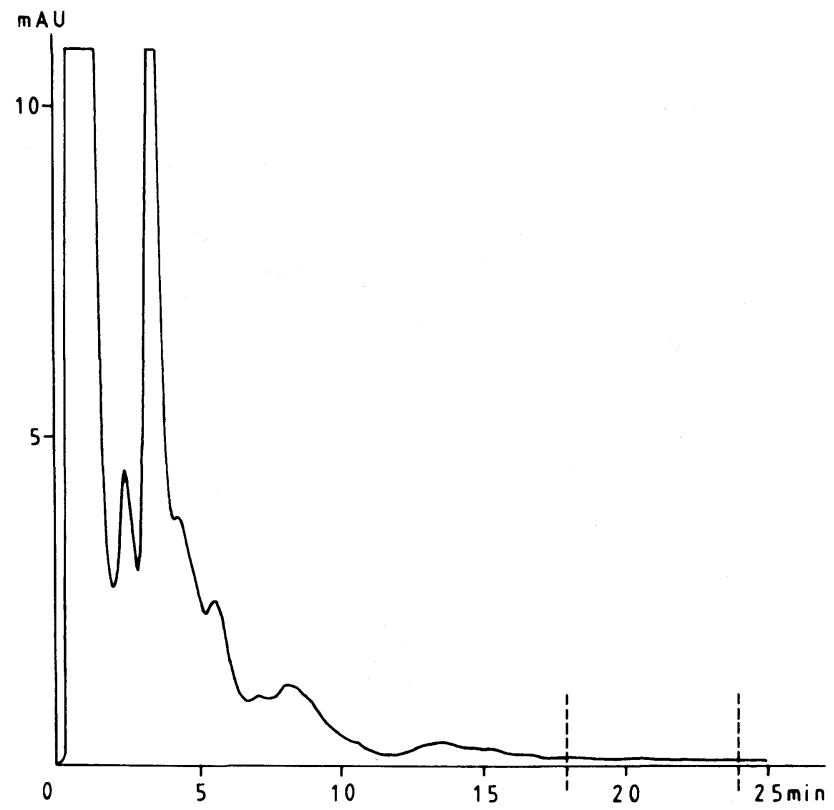

Fig. 2: Preparative HPLC of 10 ng CyA spiked skin extract. The fraction between the two dashed lines was collected and analysed by RP-HPLC.

\section{Reversed-phase HPLC}

Typical chromatograms obtained from CyA spiked skin and a sample from a psoriatic patient are shown in Fig. 3.

If the CyA analytical window and its vicinity are free of interfering peaks CyA can be determined down to concentration of $0.5 \mathrm{ng}$ using $\mathrm{CyC}$ as an internal standard. However, in some separations of thicker upper skin layers taken by lancet the result can be affected by fusion of the internal standard peak with some relative great impurity peaks. Because CyA recovery was almost quantitative in the given case the external standard method seems to be just as reliable.

The recovery was extensively checked on the $10 \mathrm{ng}$ level: it amounts to $101.3 \%$ (mean of 3 determinations, RSD $1.1 \%$ ) without skin addition and $96.8 \%$ (mean of 6 determinations, RSD $6.3 \%$ ) by the complete analysis of spiked skin samples.

The sensitivity of the analytical RP-HPLC was relatively high. By injection of $0.94 \mathrm{ng}$ CyA the signal/noise ratio was 27 . It should be theoretically possible to determine less than
$0.5 \mathrm{ng}$ CyA, if all the substances out of the skin matrix could be removed in a nearly quantitative way. Otherwise the $3 \mathrm{ng}$ CyA/sample must be considered as the lowest limit for reliable determination.

This work was done in cooperation with the Department of Dermatology of the University of Cologne; three skin samples were supplied taken by biopsy from psoriatic patients. A CyA content was found therein from 1 to 6 $\mathrm{ng} / \mathrm{mg}$ wet tissue.
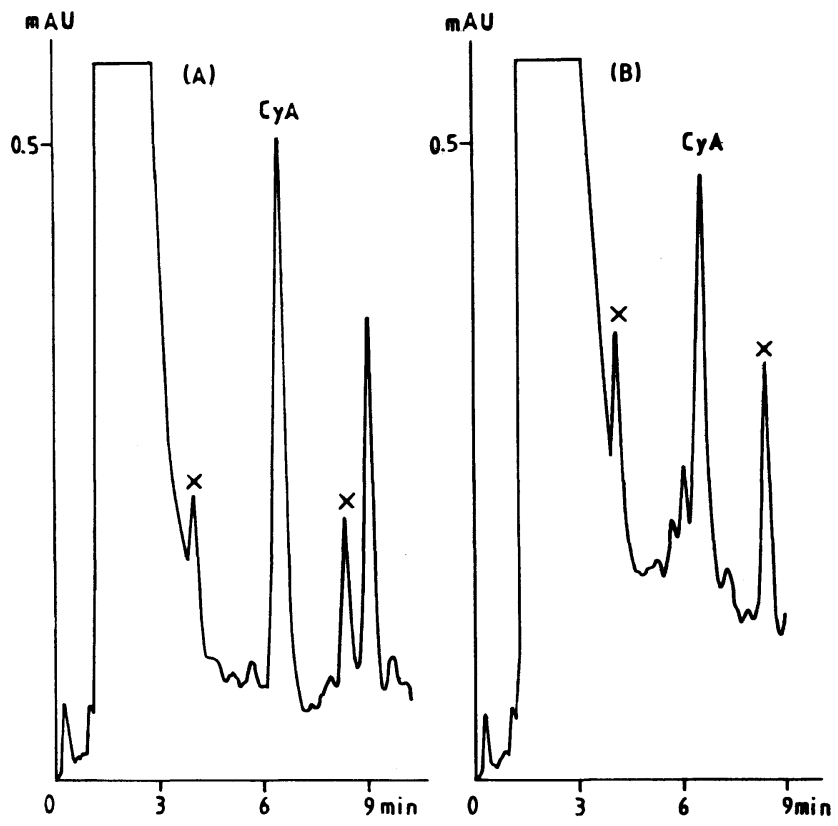

Fig. 3: RP-HPLC of purified skin extracts. (A) $10 \mathrm{ng}$ CyA spiked epidermis. (B) Skin biopsy of CyA treated psoriatic patient, app. $1 \mathrm{~mm}$ upper layer. The impurities originating from $\mathrm{CH}_{3} \mathrm{CN}$ are marked with crosses.

\section{Normal-phase HPLC}

When the skin matrix separation by preparative HPLC was insufficient and, therefore, the RP-HPLC determination was not reliable, it was possible to carry out an additional analysis with the collected CyA-effluent out of the RPHPLC column by its reinjection (after proper treatment) into the normal-phase HPLC system ${ }^{6}$. Preliminary experiments using a cyanopropylsilica column and $10 \%$ isopropanol in hexan as mobile phase gave promissing results.

Five standard analyses were carried out to prove the recovery of this step: each time $10 \mu \mathrm{l}$ of $\mathrm{CyA}$ and $\mathrm{CyC}$ stock solutions were mixed with approximately $2 \mathrm{ml}$ mobile phase collected behind the analytical RP-HPLC column and this simulated effluent was treated previous to injection like a true sample.

The recoveries of both cyclosporines ranged approximately from $75 \%$ to $90 \%$ compared to the direct standard injections of the same amounts of $\mathrm{CyA}$ and $\mathrm{CyC}$ in $15 \%$ i$\mathrm{PrOH} / \mathrm{hexane}$ but the peak areas ratio $\mathrm{CyA} / \mathrm{CyC}$ was constant (mean 1.022, RSD 4.3\%), which made the internal standard method usable. 

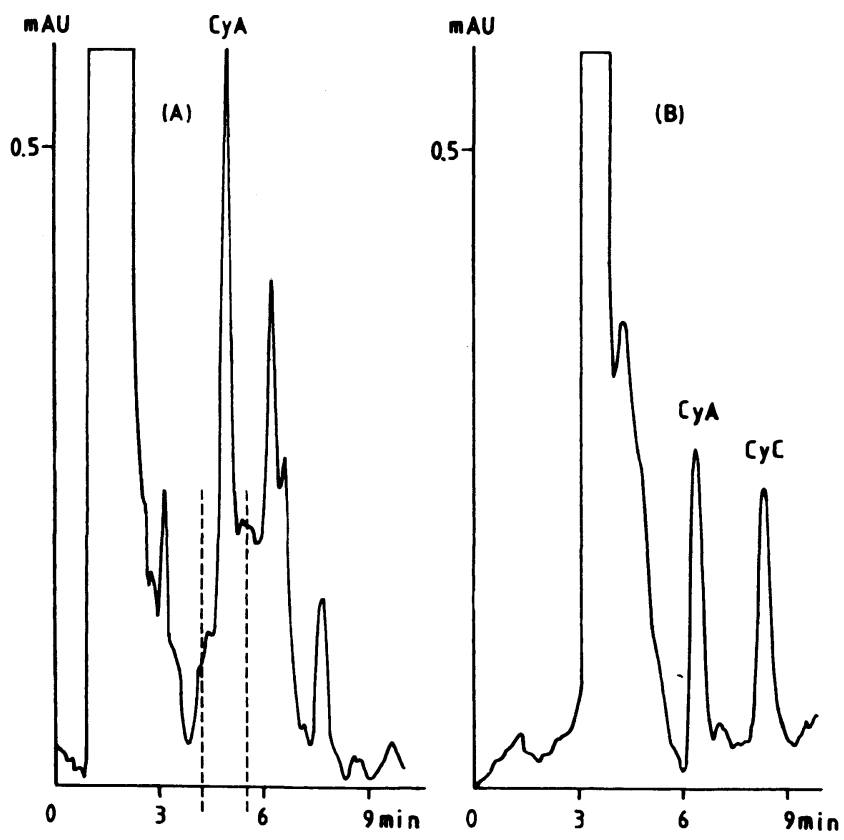

Fig. 4: Reversed- and normal-phase HPLC of not satisfactorily purified 10 ng CyA spiked skin extract. (A) RP-HPLC, recovery $102 \%$. The fraction between the two dashed lines was collected and re-analyzed by NP-HPLC (B), recovery $101 \%$.

Quantitative recoveries were achieved using fresh $2 \mathrm{ml}$ RP-HPLC analytical mobile phase instead of the one collected behind the column. At $75^{\circ} \mathrm{C}$ the surface of the modified silica is relatively strongly degraded and the released octadecylsilanol molecules create a hydrophobic cover on the glass wall, which can bind cyclosporine.

Three complete spiked skin analyses including all three HPLC steps were performed with satisfactory results. CyA amounts calculated on the base of the normal-phase HPLC ranged from $94 \%$ to $103 \%$ (mean $99.3 \%$, RSD $4.8 \%$ ). Analytical chromatograms of one of these analyses are shown in the Fig. 3.

We are grateful to Sandoz Ltd., Nürnberg, for financial support of this work and for cyclosporine standards, and to LDC Analytical for lending us the SpectroMonitor 3200 detector.

\section{References}

1 H.-J. Schulze, G. Mahrle, G. K. Steigleder, Brit. J. Dermatol. 1990, 122, 113-114.

2 W. Niederberger, M. Lemaire, G. Maurer, O. Wagner, Transplant. Proc. 1983, 15, 2419-2421.

3 O. Wagner, E. Schreier, F. Heitz, G. Maurer, Drug Metab. Dispos. 1987, 15, 377-383.

4 G. J. Fisher, E. A. Duell, B. J. Nickoloff, T. A. Annesley, J. K. Kowalke, C. N. Ellis, J. J. Voorhees, J. Invest. Dermatol. 1988, 91, 142-146.

5 L. D. Bowers, S. E. Mathews, J. Chromatogr. 1985, 333, 231-238.

6 P. E. Wallemacq, M. Lesne, J. Chromatogr., Biomed. Applic. 1987, $413,131-140$.

[Ph122] 